University of Zurich

Department of Economics

Working Paper Series

ISSN 1664-7041 (print)

ISSN 1664-705X (online)

Working Paper No. 77

\title{
Structural Change in Developing Countries: Has It Decreased Gender Inequality?
}

Michelle Rendall

May 2012 


\title{
Structural Change in Developing Countries: Has It Decreased Gender Inequality?*
}

\author{
Michelle Rendall ${ }^{\dagger}$ \\ The University of Zurich
}

May 14, 2012

\begin{abstract}
This paper examines the evolution of female labor market outcomes from 1987 to 2008 by assessing the role of changing labor demand requirements in four developing countries: Brazil, Mexico, India and Thailand. The results highlight the importance of structural change in reducing gender disparities by decreasing the labor demand for physical attributes. The results show that India, the country with the greatest physical labor requirements, exhibits the largest labor market gender inequality. In contrast, Brazil's labor requirements have followed a similar trend seen in the United States, reducing gender inequality in both wages and labor force participation.
\end{abstract}

Keywords: Structural Change; Job Tasks; Female Employment; Wage Gap; Latin America; Asia JEL Classifications: J20; J23; J24; J31; O31; O33

\footnotetext{
*I would like to thank Carolina Sanchez-Paramo, Seminar participants at EEA Oslo 2011, and two anonymous referees for valuable comments. Financial support from the European Research Council (ERC Advanced Grant IPCDP-229883) and the World Bank is gratefully acknowledged.

${ }^{\dagger}$ University of Zurich, Department of Economics, Muehlebachstrasse 86 CH-8008 Zurich. Email: michelle.rendall@econ.uzh.ch. All errors are mine.
} 


\section{INTRODUCTION}

Since WWII, women in the United States have greatly benefited from job requirements shifting away from physical attributes ("brain") toward their comparative advantage in intellectual attributes ("brawn") (see Rendall, 2010). While some of the shifting demand favoring women is related to job requirements changing intra-occupation, a large portion of the decrease in physical requirements is due to a structural shift toward services (Rendall, 2011). Hence, the last 60-years have seen an explosion in job opportunities for women in the United States, coupled with higher wages and relatively large returns to education. Can this structural transformation mechanism provide some insight into gender inequality in developing countries?

This paper examines the evolution of female labor force participation and wages from 1987 to 2008 in four developing countries (Brazil, Mexico, India and Thailand) to assess the role of structural labor demand changes on gender inequality. Specifically, the demand requirements from the United States estimated in Rendall (2010) are used to determine the ordinal ranking of occupation-industry requirements within a given country. The use of an ordinal ranking of occupations-industry pairs stems from the argument that similar jobs in different countries will be ranked approximately the same when sorted by brain and brawn requirements. For example, the following occupational brawn ranking (highest to lowest) of farmer, waiter, and accountant in the United States will be the same in Mexico and India. Thus, detailed information on United States job requirements can be used to control for the usually unobservable work requirements in other countries. This ordering of jobs by skill is able to explain some of the "micro"-foundations of gender inequality in wages and labor force participation.

Galor \& Weil (1996) were one of the first studies to suggest the link between declining physical requirements and female employment. The authors develop a theoretical model, where a mechanism of capital displacing brawn in production is linked to fertility, growth and female employment. Bacolod \& Blum (2010) provide further evidence for the United States, showing that the narrowing gender wage gap and rising earnings inequality stem from a rise in returns to cognitive and "people skills," in which women posses a comparative advantage, and a decline in returns to motor skills, in which men posses a comparative advantage. 
For developing countries, studies on the gender wage gap, and the related hypothesis of labor demand requirements, has attracted more research in Mexico than in any other country. Most Mexican studies focus on the 1980s and 1990s. Brown et al. (1999) find a widening wage gap between 1987 and 1993. According to the authors, this result can be explained by differences in the human capital endowment between men and women. In contrast, changes in the occupational distribution of men and women helped close the wage gap. The authors find that the wage gap was largest in the laborer category, consistent with the brain and brawn hypothesis explored in this study. Similarly, Artecona \& Cunningham (2002) find that trade liberalization in the 1980s widened the gender wage gap in the Mexican manufacturing sector. However, the authors conclude that this was likely due to an increased premium for men's greater skills (experience) in this sector, which is also consistent with the hypothesis proposed in this study. Gonzlez (2001) finds that post-crisis, in the mid-1990s, the demand for workers in the maquiladoras increased, increasing at the same time the demand for low-skilled female workers. ${ }^{1}$ The author concludes that this change in demand for low skilled women may have reversed the closing of the gender wage gap. These results further support the hypothesis of increasing (decreasing) physical requirements negatively impacting (benefiting) women in terms of wages and employment opportunities.

While fewer in number, some studies also hint at the impact of structural labor market changes on gender inequality in other relevant countries. In the case of Brazil, Arabsheibani et al. (2003) find a large narrowing of the gender pay gap since 1980. The authors attribute this to a substantial improvement in the position of women in the labor market. Evidence suggests that in the late 1990s, an improvement in women's endowments of human capital helped close the wage gap. Similarly, for Thailand, Nakavachara (2010), studying gender differences from 1985 to 2005, finds that increases in female education and modernization were the main factors in reducing the gender wage gap.

With the exception of Mexico, little has been done in simultaneously assessing sectoral labor allocation changes and female opportunities beyond the comparison of formal versus informal sectors, or public versus private sectoral employment. Nonetheless, Winters \& Yusuf (2007) list India, Russia, Brazil and Mexico as examples of countries actively expanding their service sectors as po-

\footnotetext{
${ }^{1} \mathrm{~A}$ maquiladora is an operation involving manufacturing in a country that has different tariff treatment from the host country.
} 
tential engines of growth. Such developments make an analysis of sectoral changes and female labor market opportunities in developing countries particularly relevant.

In summary, this study expands on the existing literature in three ways: (1) updating previous results with the latest available data; (2) providing cross-country comparisons and relating them to structural change in labor requirements; and (3) augmenting existing data with intellectual (brain) and physical (brawn) job requirements by occupation-industry pairs. Thus, this research allows the study of previously unobservable labor demand changes which affect men and women differently. This last point is key. Other research is limited by the use of highly aggregated industry indicator variables, where an entire economy is split into a few broad categories, such as agriculture, services, and industry. In contrast, computing relative job requirements by occupationindustry pairs provides a detailed representation of job characteristics present in an economy. Thus, a deeper analysis of gender inequality by occupations and industries can be undertaken without attributing all outcome differences to unobservable factors, such as discrimination.

This paper is split into two main parts. The first part presents the data, focusing on relative work requirements. Specifically, section 2 outlines aggregate labor market outcomes and section 3 discusses changes in brain and brawn requirements for the four developing countries and the United States (as a benchmark) across time and gender. The second part consists of a number of regression estimations to test for a consistent hypothesis across time and country, related to changing skill demands. Section 4, decomposes the contribution of structural change on the gender wage gap, and section 5 estimates the impact of structural change on female labor force participation and education rates. Section 6 provides policy conclusions and section 7 concludes.

\section{COUNTRY SURVEY DATA}

The World Bank Household Survey, IPUMS International, IPUMS USA, and IPUMS CPS ${ }^{2}$ provide individual-level data on demographic and economic variables such as gender, age, education,

\footnotetext{
${ }^{2}$ More precisely, The World Bank dataset of Standardized Household Surveys from Around the World, Integrated Public Use Microdata Series; The Integrated Public Use Microdata Series, International: Version 6.0 (IPUMS International, Center, 2010); the Integrated Public Use Microdata Series: Version 5.0 (IPUMS USA, Ruggles et al., 2010); and Current Population Survey: Version 3.0 (IPUMS CPS, King et al., 2010), respectively.
} 
employment, and wages for Brazil, Mexico, Thailand, India, and the United States. ${ }^{3}$ The main benefit of using these particular datasets is that they have been coded consistently across countries, allowing for a coherent cross-country comparison.

Two samples are used for each country, an employment sample and a wage sample, where the wage sample is a subset of the employment sample. Roughly 60 to 70 percent of individuals in the employment sample overlap with the the wage sample for Brazil and Mexico, while in Thailand the overlap is roughly 40 percent and slightly lower in India. Table $A .1$ summarizes sample sizes and gender composition for each country.

The employment sample includes all individuals aged 15 to 65 with employment status information (employed, unemployed or not in the labor force). Thus, this study includes everyone except individuals who are either unemployed or not in the labor force.

The wage sample includes all individuals employed with positive salary or wages. Hours worked is available for the United States, Brazil, and Mexico wages samples and is used to restrict the sample for these countries to full-time workers (35 hours per week or more). ${ }^{4}$

For the wage sample in India, the Indian Socio-Economic Survey computes wages from both cash and in-kind payments, unlike all other countries that compute wages by cash payments alone. It is impossible to decompose wages from cash and in-kind payments, since only total values in Indian Rupees are reported. Although wage estimates of in-kind payments carry, by their nature, larger measurement errors, it would be misrepresentative to eliminate these payments as they contribute to the labor compensation ("wages") for a large fraction of Indian workers. Lastly, given low female labor force participation in India (see Table 1), the wage sample is heavily male dominated.

\subsection{Labor market trends}

Table 1 summarizes labor force participation trends, where labor force participation rates include all employed, self-employed, and unemployed individuals aged 15 to $65 .^{5}$

\footnotetext{
${ }^{3}$ For detail on each country-specific datasets see Appendix $A$.

${ }^{4}$ India and Thailand do not provide hours worked within their wage samples, making a full-time restriction impossible to implement.

${ }^{5}$ While general dates are used in the following tables, some survey years are not perfectly aligned. Brazil 1987 and 1999 are estimates for 1990 and 2000. Thailand 1994, 2002 and 2006 surveys are estimates for 1995, 2000 and 2005. India surveys for 1987, 1993, 1999 and 2004 are estimates for 1990, 1995, 2000 and 2005.
} 
(Insert Table 1 here)

All countries had low female labor force participation rates in 1990, except Thailand, which, even in 1990, had a higher female employment level than the United States in 2005. Mexico and Brazil have had large female employment increases over time, mirroring the growth experienced in the United States, while India has seen only a moderate rise.

Table 2 summarizes wage gap trends for the selected country sample. All wages are deflated by country specific CPIs and normalized to weekly wages. All countries, except Mexico, have seen a large fall in the gender wage gap over time. However, Mexico and Thailand generally have small wage gaps by international standards, while India lags behind, which is consistent with other research (see for example Menon \& Rodgers, 2009).

(Insert Table 2 here)

Generally, there has been some shrinking of gender inequality over time in all countries studied. However, the results vary substantially across countries, with all the representative countries, except Thailand, lagging behind the United States in terms female labor force participation and wages. Brazil most closely resembles the United States in terms of female wages and employment. Lagging behind Brazil, women in Mexico face worse fewer opportunities. Lastly, the data points toward a much larger gap in India than anywhere else.

\section{DICTIONARY OF OCCUPATIONAL TITLE}

The household survey data provides disaggregate three- or four-digit country-specific occupation and industry classifications. Using crosswalks to map representative country-specific occupation/industry information to the United States census classifications permits the merging of the occupation-industry job information contained in the Fourth Edition (1977) and Revised Fourth Edition (1991) of the Dictionaries of Occupational Title (DOT). ${ }^{6,7}$

\footnotetext{
${ }^{6}$ Data, including documentation, is available from the Inter-university Consortium for Political and Social Research (ICPSR).

${ }^{7}$ The crosswalks, or merge keys, are available upon request.
} 
The 1977 and 1991 DOT were developed by the United States Department of Labor, who evaluated approximately 40 job requirements for more than 12,000 occupations. These 40 job requirements are organized into six broad categories.

1. General educational development measures the formal and informal educational attainment required to perform a job effectively by rating reasoning, language and mathematical development. Each reported level is primarily based on curricula taught in the United States, where the highest mathematical level is advanced calculus, and the lowest level requires basic operations, such as adding and subtracting two-digit numbers.

2. Specific vocational training is measured by the number of years a typical employee needs to aquire the job tasks essential to perform at an average level.

3. Worked aptitudes required of a worker (e.g., general intelligence, motor coordination, numerical ability) are rated on a five point scale, with the first point/level equivalent to the top ten percent of the population and the fifth level compromising the bottom ten percent of the population. The remaining 90 percent are split into three equal parts to make up the remaining levels.

4. Temperaments or adaptability required of a worker is included, where the temperament type is reported as present or absent. An example of a temperament is the ability to influence people in their opinions or judgments.

5. Physical strength requirements include a measure of strength required on the job, rated on a five point scale indicating sedentary to very heavy strength requirements, and the presence or absence of tasks such as climbing, reaching, or kneeling.

6. Evironmental conditions measure occupational exposure (presence or absence) to environmental conditions, such as extreme heat, cold and noise.

\subsection{Bridging the Datasets}

Rendall (2010) uses the DOT aggregated to three-digit Census Occupation and Industry codes 
to study changing job requirements over time in the United States. Factor analysis, or principal component analysis, similar to Ingram \& Neumann (2006), reduces the dimensionality of DOT job characteristics. Using principal component analysis allows a linear relationship between normally distributed broad skill categories (e.g., brain, brawn) and the DOT characteristics to be estimated from the associated correlation matrix. Each factor includes the job characteristics outlined in Table 3 (for additional detail on the estimation procedure and the resulting factor loadings see Rendall, 2010). ${ }^{8}$

(Insert Table 3 here)

Job requirements from the DOT are specific to the United States and there exists no direct mapping to other countries. ${ }^{9}$ This study overcomes this problem by normalizing factors (skills), following Autor et al. (2003), to percentiles of the 1990 factor distributions for each country. This method assumes that the United States skill requirement rank for each occupation-industry pair match those of the sample countries on an ordinal scale. For example, a farmer will require more brawn than an accountant in all countries.

Tables 4 and 5 summarize skill requirements for aggregate United States industries in $1990 .{ }^{10}$ Industries are sorted from low to high for both brain and brawn requirements, which is a representation of the ordinal ranking methodology used in this study. While these tables summarize skill requirements for broad industries irrespective of occupations, this study uses the disaggregated list of occupation-industry pairs available within the survey data. ${ }^{11}$

(Insert Table 4 and 5 here)

\footnotetext{
${ }^{8}$ See Schoellman (2009) for a similar use of principal component analysis with DOT data.

${ }^{9}$ Superimposing the United States factor estimates from the DOT on the Household survey samples for the four representative countries would require the strong assumption that occupations-industry pairs require the same skill set regardless of the country. The difficulty of this assumption can be clearly seen when comparing a farmer in the United States using modern technology to harvest wheat and an Indian farmer harvesting rice by hand.

${ }^{10}$ Tables $B .1$ and $B .2$ by aggregate occupations can be found in Appendix $B$.

${ }^{11}$ Due to the size of the country-specific ordinal ranking of occupation-industry pairs by skill requirements, this information is available upon request. Additionally, 4,310 occupation-industry pairs for Brazil; 3,381 for Mexico; 585 for Thailand; 3,671 for Indonesia; and 3,410 for the United States are sufficiently covered by the 12,000 occupationindustry pairs contained in the DOT, which contains data at a greater disaggregation level than country-specific Census classifications.
} 
The tables also provide the United States skill requirements on a zero-one scale for 1977 and 1991 DOT. Since there is no natural scale to factor analysis, all factors are normalized on a scale from zero to one. For example, the highest brain requirement is one and the lowest brain requirement is zero. This cardinal scale supports the consistency of the ordinal ranking methodology over time.

Additionally, the ordinal ranking of broad industries (occupations) are stable over time. That is, relative job requirements across industries (and occupations) are highly time-invariant. While physical job requirements have risen in the United States between 1977 and 1991 within industries, a large fraction of the economy-wide trend is not related to intra-job changes. Instead, the data points to a sectoral and occupational reallocation of workers to high-skilled occupation-industry pairs (see Appendix $B$ for labor shares by aggregate occupation or industries). Thus, the majority of the job requirement changes recorded in the data are caused by shifts across three-digit occupation-industry rather than within the occupation-industry pairs.

The ordinal ranking of broad industries (occupations) are stable over time. That is, relative job requirements across industries (and occupations) are highly time-invariant. While physical job requirements have risen in the United States between 1977 and 1991 within industries, a large fraction of the economy-wide trend is not related to intra-job changes. Instead, the data points to a sectoral and occupational reallocation of workers to high-skilled occupations-industries (see Appendix $B$ for labor shares by aggregate occupation or industries). Thus, the majority of the job requirement changes recorded in the data are caused by shifts across three-digit occupation-industry rather than within the occupation-industry pairs.

Furthermore, controlling for occupation-industry skill requirements together, rather than only using industry or occupation categories alone, provides additional insight into country-specific structural shifts within the labor market. For example, a secretarial occupation may have similar skill requirements in the service and manufacturing industry sectors, even though the average brawn requirements for each industry are very different. Studies aggregating results by either occupation or industry will, by definition, lose some these distributional nuances.

Note that using an ordinal skill requirement rank to link the United States factor distributions to other countries implies that all skill requirements have a mean of 50 in 1990 for each country 
in the sample. For example, all Brazilian workers in 1990 are sorted by their associated threedigit occupation-industry code using the ordinal ranking described above. The relative percentile associated with a given occupation-industry pair depends on the number of individuals working in each occupation-industry pair within the economy. Thus, as long as the ordinal sorting of occupation-industry pairs, based on United States data, does not dramatically differ from the sample country, this scaling allows a consistent study of changes over time within each country, but not across country.

More specifically, ordinal ranking does not allow for absolute cross-country comparisons. For example, it might be the case that the Indian economy is more reliant on brawn across all occupationindustry pairs than the Brazilian economy. The normalizations in 1990 to percentiles within each country will lose this absolute difference. Nonetheless, relative cross-country comparisons in timetrend comparisons are valid.

To further check the robustness of results, and to allow comparison of absolute cross-country differences in brain and brawn requirements, a second classification of occupation-industry pairs, based directly on zero-one brain and brawn scales, is developed. Using the zero-one brain and brawn scales necessitates the strong assumption that occupations/industries across countries use similar absolute levels of skill requirements. To relax this assumption, occupation-industry pairs are grouped into three categories based on their brain and brawn requirements: low, medium, and high. As seen in Table 4 and 5 (and Tables B.1 and B.2), there are three natural cut-off points at one-third and two-thirds. E.g., occupation-industry pairs with brain requirements below 0.33 are categorized as low-brain jobs and above 0.66 as high-brain jobs.

\subsection{Country-Specific Structural Transformation}

Figures 1 and 2 show how brain and brawn factors evolve over time by country. That is, the re-scaling of the ordinal ranking of skill requirements by occupation-industry pairs to percentiles implies that the average factor requirement deviations from the economy-wide mean in 1990 are zero. For the United States, 1950 data is also provided to highlight the impact of structural change on the evolution of brain versus brawn job requirements since WWII. The column for 
2005/2008 (latest available) provides relative factor requirement changes using the 1991 DOT, while the remaining data uses the 1977 DOT sorting.

\section{(Insert Figure 1 here)}

All countries, except India, saw structural change shift their brain demand distributions upward. Additionally, the change is similar when using either the 1977 or 1991 DOT classifications, with the exception of Thailand. Thailand only provided one-digit aggregate industry classifications resulting in a loss of information when bridging skill requirements (see Appendix $A$ for further details). Consequently, using the 1977 or 1991 DOT classification can lead to relatively large differences depending on which survey is used. ${ }^{12}$

\section{(Insert Figure 2 here)}

In contrast, all countries saw a downward shift in brawn requirements since 1990. However, there are large cross-country differences with respect to the magnitude of shifting brawn requirements. Thailand experienced the largest relative decrease in brawn requirements, decreasing 15 percentile points since 1990. India experienced the smallest shift in brawn, basically staying flat with a decrease of 0.2 percentile points.

To allow absolute cross-country comparisons by years, Figures 3 and 4 show the breakdown of workers in 1990 and 2005 by broad brain and brawn job categories (low, medium, and high). This cross-country comparison clearly illustrates the gap between the United States and the sample countries. Thailand added the most workers in occupation-industry pairs requiring medium-brain levels, while Brazil and Mexico have a larger share of high-brain occupations.

\section{(Insert Figure 3 here)}

Similarly, the sample countries also lag the United States in terms of shifting away from brawn occupations/industries. Thailand saw a considerable decrease in high-brawn employment, with a

\footnotetext{
${ }^{12}$ However, this is only the case when analyzing shifts in the brain distribution over time. The gender analysis in sections 4 and 5 are robust to both 1977 and 1991 DOT classifications. For this analysis, the importance lies in differences across gender. If relative gender differences are unaffected by the 1977 versus 1991 DOT then the overall results are unaffected.
} 
simultaneous increase in medium-brawn employment. Consistent with the country-specific scaling, the cross-country comparison shows that India experienced the slowest structural change of all sample countries. This slow structural transformation in India is also apparent when looking at sectoral labor shares by aggregate industries and occupations (see Appendix B).

\section{(Insert Figure 4 here)}

\subsection{Cross-Country Comparisons by Gender}

To illustrate how gender-specific skill requirements have evolved over time, Figures 5 and 6 graph shares by gender for brain and brawn categories in 1990 and 2005. Apart from Mexico, both genders in all countries increased their brain "supplies." Gender-specific brawn "supplies" show large cross-country differences.

\section{(Insert Figure 5 and 6 here)}

Based on the gender averages, there is a surprisingly high concentration of women in the high(and medium-) brawn jobs for Thailand and India.

Brazil has closely followed the United States' growth path. However, Brazil still has considerably higher brawn and lower brain requirements than the United States. Additionally, Brazil saw a large rise in the share of women working in low-brawn occupations (see Appendix $B$ ).

In Mexico, the employment of low-skilled workers in the maquiladoras can explain the rise in higher brawn jobs and lower brain jobs for women (see Gonzlez, 2001). In contrast, men's employment has followed the typical structural transformation path, with an increasing share in low-brawn jobs and a rising share in high-brain jobs.

Thailand experienced a relatively quick shifting of women from low- to medium-brain employment. However, like India, Thailand has added few high-brain occupations and thus lags both Brazil and Mexico by a large margin. In terms of brawn, Thailand has seen an equal movement from high-brawn to medium-brawn occupations for both men and women. Women and men are equally represented in agriculture, manufacturing, and services in Thailand. 
In contrast to the other countries, Indian women work in occupations requiring high brawn levels compared to men. The explantation underpinning the data is that Indian women are mostly employed in the agricultural sector to likely meet some subsistence level of income (see Klasen \& Pieters, 2012, for "push" versus "pull" arguments in the case of India's female employment.). Thus, low-skilled women find themselves employed in a brawn intensive occupation that is considered predominantly "subsistence work." Consequently, women are virtually missing in the service sector where brawn requirements are lowest. Additionally, Indian brain requirements further confirm the small structural changes over time.

\section{WAGE GAP ANALYSIS}

In order to assess the relationship between structural changes in country-specific labor markets, via changing job skill requirements, and the gender wage gap, a Wellington wage gap decomposition is utilized (Wellington, 1993). The primary purpose of this regression analysis is to gain a better understanding of the effects of structural change on the labor market with respect to wages.

\subsection{Wage gap decomposition}

The decreasing wage gap over time is decomposed using a similar method to Black \& Spitz-Oener (2010). This method is based on the wage decomposition proposed by Wellington (1993).

The household data used in this study records skill requirements corresponding to jobs. This does not necessarily mean that these jobs reflect the entire skill set of individuals they employ. More specifically, if individuals could sort, on average, into jobs that match their innate skill set, the expected returns for each skill type should equalize across gender conditional on skill level. Thus, any difference in gender-specific skill returns implies either a mismatch in the employment of individual skills or gender discrimination that varies across skill type.

For example, assume a female and male ceteris paribus have the same brain and brawn endowments. If the female faces a lower wage than her male counterpart, this could be due to three reasons. 
Case 1: The first possible reason is that the female is working in an occupation that does not fully employ her brain and brawn endowments, where the male is working in an occupation that fully utilizes his skill endowments. This mismatch between skill endowments and occupation is further discussed in Section 44.2.

Case 2: The second possible reason is discrimination by gender, suggesting skill returns do not differ by gender. This is the assumption used within this section.

Case 3: The third possible reason is asymmetrical discrimination across skill types, where employers discriminate against women based on either brain or brawn, but not both in the same magnitude. This case is impossible to investigate. Consequently, this study defaults to case 2 above rather than making non-standard assumptions on a discrimination measure interacted with skill requirements.

While the assumption on equal skill returns across gender implies that men and women, on average, are compensated identically with respect to skill, it does not imply that men and women are perfect substitutes in the labor market (consistent with Acemoglu et al., 2004). ${ }^{13}$ That is, it is only assumed that equal amounts of brain (or brawn) are perfect substitutes, without regard to the gender of the employee. Ergo, the following pooled Mincer wage regression for men and women is estimated,

$$
\ln \left(w_{i t}^{g}\right)=Z_{i t}^{g} \alpha_{t}+M_{i} \lambda_{t}+X_{i t}^{g} \beta_{t}+\epsilon_{i t}^{g} \quad \text { with } g=\{m, f\}
$$

where $Z_{i t}^{g}$ are individuals characteristics, $M_{i}$ is an indicator variable for males, and $X_{i t}^{g}$ are skill (brain and brawn) requirements.

Given factor requirements, $X_{i t}^{g}$ and estimates of "prices," $\hat{\beta}_{t}$, the decomposition of individual

\footnotetext{
${ }^{13}$ Computing the degree of substitution between men and women is beyond the purpose of this study.
} 
traits and factor effects on wage changes is given by,

$$
\begin{aligned}
\left(\bar{\omega}_{i t}^{m}-\bar{\omega}_{i t}^{f}\right)- & \left(\bar{\omega}_{i 0}^{m}-\bar{\omega}_{i 0}^{f}\right)= \\
& \underbrace{\left\{\left(Z_{t}^{m}-Z_{0}^{m}\right)-\left(Z_{t}^{f}-Z_{0}^{f}\right)\right\} \bar{\alpha}_{t}}_{\text {Standard Endowment } \Delta_{t}}+\underbrace{\left(\bar{Z}^{m}-\bar{Z}^{f}\right)\left(\hat{\alpha}_{t}-\hat{\alpha}_{0}\right)+\left(\hat{\lambda}_{t}-\hat{\lambda}_{0}\right)}_{\text {Standard Price } \Delta_{t}}+ \\
& \underbrace{\left\{\left(X_{t}^{m}-X_{0}^{m}\right)-\left(X_{t}^{f}-X_{0}^{f}\right)\right\}}_{\text {Skill Endowment } \Delta_{t}} \bar{\beta}_{t}+\underbrace{\left(\bar{X}^{m}-\bar{X}^{f}\right)\left(\hat{\beta}_{t}-\hat{\beta}_{0}\right)}_{\text {Skill Price } \Delta_{t}},
\end{aligned}
$$

where $\omega$ is the average (natural) log of wages, and bars without time subscripts denote averages over time, e.g., $\bar{Z}^{m}=\frac{1}{2}\left(1^{\prime} Z_{0}^{m}+1^{\prime} Z_{t}^{m}\right)$.

Thus, the wage gap from period 0 to $t$ is decomposed into four categories.

1. Relative changes in standard male and standard female characteristics, given average returns.

2. Relative price changes, given average male and female standard characteristics (including changes in gender discrimination $\lambda$ ).

3. Relative changes in skill endowments, given average skill prices.

4. Relative skill price changes, given average male and female skills.

The first two terms in equation (2) are standard in a typical gender wage decomposition. These individual characteristics include age, education, marital status, and race to capture demographic changes, and a gender dummy to capture changes in discrimination. For the developing countries, $Z_{i t}^{g}$ also includes an urban/rural location indicator dummy, but not race due to lack of data. ${ }^{14}$

With estimates of brain and brawn by occupation-industry pair, the last two terms in equation (2) capture some of the usually unexplained unobservables. These terms quanitfy the importance of demand changes in brain and brawn for generating greater gender equality (for a similar study on Germany see Black \& Spitz-Oener, 2010)

Table 6 lists the Mincer wage regression results for skills based on equation (1). All other coefficients from the Mincer wage regression can be found in Appendix $C{ }^{15}$ The coefficients on

\footnotetext{
${ }^{14}$ In addition, Brazil does not have any marital status information.

${ }^{15}$ The Mincer wage regressions have standard R-squares (see $C$ ).
} 
skill factors are highly significant, with the absolute returns to brain being larger than the absolute returns to brawn in the United States, Brazil, and Mexico. Higher brawn occupations in the United States and Brazil receive a premium (positive coefficients). The inverse is true in Mexico, Thailand, and India. I.e., higher brawn requirements in these countries lead to lower average wages (negative coefficients).

\section{(Insert Table 6 here)}

Looking at trends between 1990 and 2005, returns increased for brain and fell for brawn endowments in the United States. For the developing countries studied, the evidence is mixed. Mexico and India mirror the trends in the United States with rising brain returns and falling brawn returns over time. In complete contrast, Thailand experienced rising brawn returns and decreasing brain returns over time. Specifically, the wage penalty on high-brawn occupations decreased between 1990 and 2005. Looking at the results for Brazil, both brain and brawn returns decreased during this time. However, the relative drop was larger in brawn, consistent with brain skills becoming relatively more valuable than brawn, as in the United States, Mexico, and India. Thus, all countries studied, with the exception of Thailand, have seen a relative price shift from brawn to brain.

Table 7 summarizes the contribution each factor makes in closing the gender wage gap. The table is organized as follows,

Column 1 shows the predicted changes in the relative gender wage gap over time. The gender wage gap closed for all countries, except Mexico. This result is consistent with the rise in maquiladoras in Mexico. The largest explained change in the gender wage gap occurred in India, where the gap shrank by 51 percentage points.

Column 2 measures the percentage point contribution to the closing gap in terms of changing endowments. I.e., changes in individual characteristics in the United States, $Z^{m}$ and $Z^{f}$, can explain 26.4 percent of the 10.8 percentage point narrowing of the gender wage gap.

Column 3 contains the closing gender wage gap contribution resulting from changing returns to individual characteristics. For example, changes in the returns to individual characteristics 
in Mexico explain 201.2 percent of the widening wage gap from 1990 to $2005 .^{16}$

Column 4 lists the contribution attributable to changes in brain skill endowments.

Column 5 lists the contribution attributable to changes in brawn skill endowments.

Column 6 adds the brain and brawn skill endowment contributions.

Column 7 shows the contribution attributed to changes in brain skill returns.

Column 8 shows the contribution attributed to changes in brawn skill returns.

Column 9 adds the contributions from changes in brain and brawn skill returns.

Column 10 adds the effect of all skill endowments and price changes (column 6 and 9).

\section{(Insert Table 7 here)}

In the case of Mexico, where the gender wage gap increased, a negative coefficient indicates a contribution to closing the wage gape. Thus, the changes in brain returns closed the wage gap by roughly 2.7 percentage points. ${ }^{17}$

In summary, the results presented in Table 7 indicate that the United States and Brazil are similar. However, the contribution of skill changes in closing the gender wage gap are considerably larger in Brazil, explaining up to half the closing wage gap. This picture is complicated by the fall in brain returns in Brazil (see Table 6), which led to a widening gap. Consistent with the changes in brain "supplies" by gender in Mexico, women work less in brain intensive occupations, and, therefore, increasing returns to brain contributed to the widening gender wage gap. The results for Thailand and India are less clear and are not easily compared to the other sample countries. This outcome is not necessarily surprising given the significantly different skill structure in these two economies. Part of the results can be attributed to the large agricultural sectors in India and Thailand, where men have a comparative brawn advantage (Pitt et al., 2010). Therefore, a

\footnotetext{
${ }^{16}$ Since all contributions add up to 100 percent, it is possible for an individual contribution to explain more than the observed closing wage gap or even a widening wage gap (positive sign).

$17(-5.9) *(-46.1) / 100)$
} 
potential mismatch between individual abilities and job skill requirements exists. The particular issue of mismatch is discussed in-detail within the next sub-section. ${ }^{18}$

\subsection{Thailand and India: Limited matching opportunities}

Figure 6 suggest a large allocation of women in higher brawn jobs in India and Thailand. Thailand has partially reversed the high-brawn structure of its economy since 1990, but is still more brawnreliant than Brazil and Mexico. In addition, the employment shares for these countries point to large agricultural sectors as the main cause of this gender-specific brawn allocation (see Appendix $B$ ). The existence of a large share of women working in agriculture and manufacturing is commonly linked to meeting basic subsistence levels of consumption in developing nations (see Klasen \& Pieters, 2012, for empirical results confirming this hypothesis in India). Therefore, women in India may not have the luxury of matching their skill sets to occupations requirements.

This explanation suggests that revising the Mincer wage regression from equation (1) to allow skill returns to differ across men and women might be a prudent assumption given the potential mismatch in skill requirements with innate abilities. ${ }^{19}$

Recalculating Table 7 using factor returns that are allowed to vary by gender means that two Mincer wage regressions are necessary rather than one pooled regression for the economy,

$$
\ln \left(w_{i t}^{g}\right)=Y_{i t}^{g} \gamma_{t}^{g}+\epsilon_{i t}^{g} \quad \text { for } g=\{m, f\} .
$$

\footnotetext{
${ }^{18}$ The decomposition results are robust to different specifications, i.e., including interaction terms of individual characteristics with gender or using the 1991 DOT scales does not alter the conclusions. The results are also qualitatively robust to inclusion of the dummy variable grouping of occupations-industry pairs. In using the dummy variable approach for job skill requirements, some detail is lost in the grouping. This leads to different contributions toward changes in skill endowment. Nevertheless, the qualitative results are comparable with the ordinal ranking method. The full set of decomposition results are available upon request.

${ }^{19}$ Alternatively, this can also be interpreted as, at a given skill level men and women cannot perfectly substitute the same amount of brain/brawn, but are still able to match perfectly to occupation requirements. This alternative explanation suggests gender discrimination as in Case 3 from section 4 above.
} 
The wage decomposition is now summarized as,

$$
\begin{aligned}
\left(\bar{\omega}_{i t}^{m}-\bar{\omega}_{i t}^{f}\right)- & \left(\bar{\omega}_{i 0}^{m}-\bar{\omega}_{i 0}^{f}\right)= \\
& \underbrace{\bar{\gamma}_{t}^{m}\left(Y_{t}^{m}-Y_{0}^{m}\right)}_{\text {Endowment } \Delta_{t}^{m}}-\underbrace{\bar{\gamma}_{t}^{f}\left(Y_{t}^{f}-Y_{0}^{f}\right)}_{\text {Endowment } \Delta_{t}^{f}}+\underbrace{\bar{Y}_{t}^{m}\left(\hat{\gamma}_{t}^{m}-\hat{\gamma}_{0}^{m}\right)}_{\text {Price } \Delta_{t}^{m}}-\underbrace{\bar{Y}_{t}^{f}\left(\hat{\gamma}_{t}^{f}-\hat{\gamma}_{0}^{f}\right)}_{\text {Price } \Delta_{t}^{f}},
\end{aligned}
$$

where $Y_{i t}^{g}=\left(Z_{i t}^{g}, X_{i t}^{g}\right)$, and $\hat{\gamma}_{t}^{g}=\left(\hat{\alpha}_{t}^{g}, \hat{\beta}_{t}^{g}\right)$. That is, the decomposition of endowment and price changes is now identical for both the standard characteristics and the skill requirements.

The wage decomposition results in Table 8 and 9 , discussed in detail below, provide solid evidence supporting a mismatch in innate ability and skill requirements in 1990, and a reversal of the mismatch by 2005 for Thailand, but not India.

(Insert Table 8 here)

\subsubsection{Thailand}

The revised results for Thailand in Table 8 support the idea that changes in skill returns have had a large impact on the closing wage gap, with brain and brawn returns explaining roughly two-thirds of the closing gap combined. The results for skill endowment estimates are virtually unchanged. These results are not surprising given the Mincer wage coefficients (see Table 9).

(Insert Table 9 here)

While the returns to brain are similar for men and women in 1990, women face a much larger brawn penalty of -1.128 versus -0.632 . In contrast, the returns to brain in 2005 are slightly larger for women at 0.202 versus 0.149 , but the returns to brawn have now equalized $(-0.571 \approx-0.516)$. These results suggest that the previous lack of appropriate job opportunities, due to the high-brawn structure in Thailand, might have been reversed by 2005. This structural shift benefited women in terms of better occupational matching and similar returns. Furthermore, based on the the results in Table 9, occupational mismatch was a negligible issue by 2005 . 


\subsubsection{India}

Allowing for differing returns by gender leaves the results on skill contributions for India almost unchanged. Specifically, changes in brawn endowments still contribute roughly 13 percent to the closing wage gap, while and changes in brain endowments contribute five percent. Additionaly, changes in skill returns still have a negative impact, moving from minus six percent to minus nine percent. Table 9 shows that brain returns increased similarly for both sexes in India, while brawn returns simultaneously fell in similar magnitudes. Therefore, the initial wage decomposition did not change substantially.

\section{SHARE ANALYSIS}

This section analyzes how the actual country-specific changes in skill demands have affected aggregate female employment shares and education rates. To make a quantitative assessment about the nature of female employment ratios and education rates related to skill, a similar approach to Autor et al. (2003) is adopted. Ergo, three regressions are estimated for each country to determine the impact of these specific skill demand changes on both female employment and education rates by gender.

First, female employment shares for given occupation-industry pairs, $j$, and a base year, $t$, are regressed on skill measures, $X^{j}$. This is,

$$
\text { Share }^{j}=\alpha+\sum_{i=1}^{2} \zeta_{i} X_{i}^{j}+\epsilon_{i}
$$

The estimated factor coefficients are then used to compute hypothetical increases in shares,

$$
\Delta_{T-t} \text { Share }^{j}=\sum_{i=1}^{2} \hat{\zeta}_{i} \Delta_{T-t} X_{i}^{j}
$$

between the end year $T$, and base year $t$, where $X_{1}^{j}$ are actual brain skill demands, and $X_{2}^{j}$ are actual brawn skill demands for occupation-industry $j$.

Similarly, the estimation method from equations (5) and (6) are used to quantify the effects of 
changing skill demands on education rates. For this purpose, equation (5) is estimated twice, one for each gender. Thus, the female-to-male employment share in equations (5) and (6) is replaced by a measure of female and male education (secondary education graduates-to-drop outs ratio).

The hypothesis for this analysis is that occupation-industry pairs with high brain requirements and low brawn requirements should be primarily adding educated female workers to their laborforce.

\subsection{Skill effects on participation}

Table 10 summarizes the predicted female employment shares using the 1977 DOT. $^{20}$

(Insert Table 10 here)

For all countries, the largest predicted effect on rising female-to-male employment results from falling brawn factor demand. This result confirms the null hypothesis, i.e., that occupation-industry pairs with low brawn requirements aid female employment. Falling brawn demand leads to an increase in female-to-male employment of four percentage points in Thailand. The decrease in brawn demand in Brazil produces a three percentage point increase in female-to-male employment ratio.

Focusing on intellectual skill requirements, rising brain factor demand had the largest impact in Brazil, with the female-to-male employment ratio dropping nearly two percentage points. This negative effect offset the gain from falling brawn demand, leading to an estimated 1.1 percentage point net rise in relative female employment, compared to almost eight percentage points in the data. In the case of Mexico, changes in brain requirements only had a small effect. Therefore, just under a quarter of the overall rise in the female-to-male employment ratio seen in Mexico is explained. For Thailand, the data presents a small rise of less than one percentage point over the past 15 years, which should be viewed in the context of its high initial female labor force participation. However, the predicted rise is similar to Mexico. As expected, given India's lack of structural change over the last 15 years, equation (6) estimates a virtually unchanged female-tomale employment ratio over the time period.

\footnotetext{
${ }^{20}$ The last year is 2005, except for Brazil and Mexico where it is 2008, with the results for 2005 being comparable. Moreover, using the 1991 DOT does not change the general results.
} 
The driving forces behind the predicted increases in female employment in Table 10 can be directly inferred from the regression coefficients from equation (5), listed in Table $11 .^{21}$

\section{(Insert Table 11 here)}

For the United States, Mexico, and Brazil, the coefficients on brawn are more negative than the brain coefficients (both coefficients are negative). That is, higher brawn requirements lead to fewer women entering the labor force. In addition, note that higher brain requirements also lead to smaller female labor ratios, but to a lesser degree. In contrast, the coefficient on brawn in India is positive, i.e., if the agricultural sector expands, equation (6) implies relatively more women (compared to men) will enter the labor force. However, given the large gender wage gap in India, and the comparative advantage of men in high-brawn jobs, this effect is most likely a product of a subsistence labor force participation requirement (Pitt et al., 2010) .

Despite the obvious cross-country estimation differences, it can be concluded that falling brawn requirements have, in general, a large positive impact on the female-to-male employment ratio.

\section{$5.2 \quad$ Skill effects on education}

As estimated in section 44.1, part of the rise in female wages is explained by changes in the individual traits of the labor force, which includes education. Moreover, Mincer wage regression results generally show an increase in the returns to education over time (see Appendix $C$ ). However, part of the increase in educational attainment can be directly linked to changes in skill demand. This means that an economy with high brain requirements should be correlated with an educated workforce. Similarly, some jobs with low-brawn requirements might also require higher brain and, therefore, more education. The estimation here focuses on differences by gender for completed secondary education rates $^{22}$

Table 12 provides an estimate of how changes in brain and brawn demand have affected the share of educated individuals by gender in each country. The rise in the share of individuals who

\footnotetext{
${ }^{21} \mathrm{R}$-squares for the regressions summarized in Table 11 range from 0.195 for India to 0.394 for Mexico. Moreover, the estimated coefficients of skill contributions are robust, that is, using DOT 1991 or the categorical sorting of occupations does not alter the general result.

${ }^{22}$ College-level education is still rare in most developing countries relative to developed countries.
} 
have completed secondary education was largest in Brazil and Mexico. While India ranked last in this measure, it still produced a 10 percentage point increase over the past 15 years.

(Insert Table 12 here)

Using equation (6), the predicted change in educational attainment greatly varies across countries. This is not due to differences in country-specific coefficient estimates, but rather differences in the magnitude and direction of the structural transformation since 1990. More precisely, Table 13 provides the estimated $\hat{\zeta}$ coefficient from equation (5). ${ }^{23}$

(Insert Table 13 here)

The coefficient signs are consistent across country. That is, a rise in brawn demands lowers the incentives to educate and an increase in brain demands promotes education. Furthermore, aside from the relatively small negative impact of brawn in the United States, the magnitudes across countries are also similar. Ergo, differences in predicted education shares across countries in Table 13 come from differences in structural change over the past 15 years. For example, Thailand, a country with a large fall in brawn demand, shows a large predicted increase in education rates. In contrast, India, a country with little structural transformation in the labor market to date, shows only a small predicted impact on education regardless of skill type.

\section{POLICY IMPLICATIONS}

The wage analysis of section 4 strongly suggests that falling brawn requirements and rising brain requirements can have a large impact on women's labor market outcomes relative to men.

Brazil is a clear example of rising brain requirements and falling brawn requirements significantly closing the gender wage gap. In contrast, India is a striking counterexample, where women work primarily in the highly brawn dependent agricultural sector. Thailand is a good example of a country that experienced major structural transformation within the labor market. This has allowed

\footnotetext{
${ }^{23} \mathrm{R}$-squares are in general higher than in the gender regression 11 . However, the R-squared for Indian women is considerable lower than the other samples with 0.286. Otherwise R-squares range from 0.413 for Mexican women to 0.558 for Brazilian women.
} 
Thai women greater labor market flexibility and better opportunities to match innate abilities with skill requirements. While some of the gains in Mexico were undone by the rise of maquiladoras in the 1990s, it could be argued that, as countries move along the development path and become richer, gender equality should naturally follow. However, at the same time, policy makers should promote an open environment with respect to education and employment opportunities for both genders. In particular, improving the quality of education will likely help strengthen and develop women's comparative advantage in brain endowments. This policy recommendation is supported by findings in Pitt et al. (2010) for Bangladesh and Klasen \& Pieters (2012) for India.

Mexico also provides a cautionary tale, as suggested by Gonzlez (2001). Mexico pursued manufacturing sector growth in the 1990s. This lead to diminishing returns to brain endowments, and was considered counterproductive when accounting for the effects on female employment opportunities. Thus, if improving gender inequality is a goal, policy makers should encourage the development of service sector employment. India has started moving along this path relatively recently with its information technology focus (see Winters \& Yusuf, 2007), and the results of this paper suggest this is a good first-step.

The results on educational attainment confirm the policy suggestions from above. Specifically, fostering a good environment for high-quality education is extremely important. However, as can be seen from the predicted gender employment ratios in all countries, higher brain demands still favor men. This means that equal access to education is imperative for the strengthening of female employment opportunities.

\section{CONCLUSION}

This study set out to explore the effects of structural change on gender inequality in the labor market, via a rise in intellectual job requirements and falling physical requirements, in four representative developing countries: Brazil, India, Mexico, and Thailand. The experience of these four developing countries, each at a different stages of the development process, are assessed against the United States. The United States provides occupation-industry skill requirements to construct a set of country-specific and cross-country comparative labor input requirements. These inputs 
are based on a robust merging of datasets for each country spanning 1987 to 2008, which are then analyzed using: (1) Wellington wage decompositions; (2) regression based female employment share predictions; and (3) regression based gender educational attainment predictions.

The results highlight the effects of structural transformation, in terms of rising brain and falling brawn requirements, on gender inequality in wages and employment shares. The wage decomposition, female employment shares, and education level results indicate that countries with lower brawn requirements, or countries in which women can take advantage of their comparative advantage in brain, provide better labor market opportunities. Thus, the size and strength of the results support the importance of rising brain requirements and falling brawn requirements in helping women improve their labor market outcomes over time.

Within the four country sample, Brazil most closely mirrors the structural transformation in factor demands seen in the United States. Thailand similarly saw an increase in brain demands and a decrease in brawn demands, but lags Brazil. Mexico's experience is punctuated by the rise of the manufacturing sector in the 1990s (i.e., maquiladora), thus lowering the brain demand in the labor market. India, provides an example where subsistence requirements continue to play a significant role in shaping employment opportunities.

Given the results, policies focused on expanding service sector employment will directly promote specific structural transformation that is especially beneficial in addressing gender inequality in the labor market. A growing service sector can also be an engine of growth, in that individual skill endowments can be more efficiently matched to employment opportunities, thus improving labor market efficiency and output. Such pro-service sector policies, currently pursued in some developing countries (see Winters \& Yusuf, 2007), can lead to an improvement in gender equality, provided women are able to access newly created service sector jobs and have the proper education to compete with men in high-brain occupations.

\section{References}

Acemoglu, D., Autor, D. H., \& Lyle, D. (2004). Women, War, and Wages: The Effect of Female Labor Supply on the Wage Structure at Midcentury. Journal of Political Economy, 112(3), 
$497-551$.

Arabsheibani, G. R., Carneiro, F. G., \& Henley, A. (2003). Gender Wage Differentials in Brazil : Trends over a Turbulent Era. Policy Research Working Paper Series 3148, The World Bank.

Artecona, R. \& Cunningham, W. (2002). Effects of Trade Liberalization on the Gender Wage Gap in Mexico. Background paper for Engendering Development 21, The World Bank.

Autor, D. H., Levy, F., \& Murnane, R. J. (2003). The Skill Content Of Recent Technological Change: An Empirical Exploration. The Quarterly Journal of Economics, 118(4), 1279-1333.

Bacolod, M. P. \& Blum, B. S. (2010). Two Sides of the Same Coin: U.S. "Residual" Inequality and the Gender Gap. Journal of Human Resources, 45(1), 197-242.

Black, S. E. \& Spitz-Oener, A. (2010). Explaining Women's Success: Technological Change and the Skill Content of Women's Work. The Review of Economics and Statistics, 92(1), 187-194.

Brown, C. J., Pagan, J. A., \& Rodriguez-Oreggia, E. (1999). Occupational Attainment and Gender Earnings Differentials in Mexico. Industrial and Labor Relations Review, 53(1), 123-135.

Center, M. P. (2010). Integrated Public Use Microdata Series (IPUMS) - International: Version 6.0 [Machine-readable database]. Minneapolis: University of Minnesota.

Galor, O. \& Weil, D. N. (1996). The Gender Gap, Fertility, and Growth. American Economic Review, 86(3), 374-87.

Gonzlez, L. M. (2001). Wage Inequality and the Gender Wage Gap in Mexico. Economia Mexicana Nueva Epoca, (2), 291-323.

Ingram, B. F. \& Neumann, G. R. (2006). The Returns to Skill. Labour Economics, 13(1), 35-59.

King, M., Ruggles, S., Alexander, J. T., Flood, S., Genadek, K., Schroeder, M. B., Trampe, B., \& Vick, R. (2010). Integrated Public Use Microdata Series, Current Population Survey: Version 3.0. [Machine-readable database]. Minneapolis: University of Minnesota. 
Klasen, S. \& Pieters, J. (2012). Push or Pull? Drivers of Female Labor Force Participation during India's Economic Boom. IZA Discussion Papers 6395, Institute for the Study of Labor (IZA).

Menon, N. \& Rodgers, Y. v. d. M. (2009). International Trade and the Gender Wage Gap: New Evidence from India's Manufacturing Sector. World Development, 37(5), 965-981.

Montenegro, C. E. \& Hirn, M. L. (2008). A New Disaggregated Set of Labor Market Indicators using Standardized Household Surveys from Around the World. Technical report.

Nakavachara, V. (2010). Superior Female Education: Explaining the Gender Earnings Gap Trend in Thailand. Journal of Asian Economics, 21(2), 198-218.

Pitt, M. M., Rosenzweig, M., \& Hassan, N. (2010). Human Capital Investment and the Gender Division of Labor. Working Papers 989, Economic Growth Center, Yale University.

Rendall, M. (2010). Brain versus Brawn: the Realization of Women's Comparative Advantage. IEW - Working Papers 491, Institute for Empirical Research in Economics - IEW.

Rendall, M. (2011). Rise of the service sector and female market work: Europe vs US. Technical report, University of Zurich.

Ruggles, S., Alexander, J. T., Genadek, K., Goeken, R., Schroeder, M. B., \& Sobek, M. (2010). Integrated Public Use Microdata Series: Version 5.0 [Machine-readable database]. Minneapolis: University of Minnesota.

Schoellman, T. (2009). The Occupations and Human Capital of U.S. Immigrants. EERI Research Paper Series EERI RP 2009 19, Economics and Econometrics Research Institute (EERI).

Wellington, A. J. (1993). Changes in the Male/Female Wage Gap, 1976-1985. Journal of Human Resources, 29(2), 383-411.

Winters, L. A. \& Yusuf, S. (2007). Dancing with Giants : China, India, and the Global Economy. World Bank ; Institute of Policy Studies, Washington, DC : Singapore. 


\section{Tables}

Table 1: Labor Force Participation (Percentage Points)

\begin{tabular}{ccccccccccc}
\hline \multirow{2}{*}{ Year } & \multicolumn{3}{c}{ USA } & \multicolumn{3}{c}{ Brazil } & \multicolumn{3}{c}{ Mexico } & \multicolumn{2}{c}{ Thailand } & \multicolumn{2}{c}{ India } \\
& M & F & M & F & M & F & M & F & M & F \\
\cline { 2 - 11 } 1950 & 86 & 33 & & & & & & & & \\
& $\cdots$ & & & & & & & & & \\
1990 & 83 & 66 & 92 & 46 & 87 & 24 & 95 & 79 & 94 & 33 \\
1995 & 82 & 68 & 90 & 53 & & & 95 & 76 & 94 & 39 \\
2000 & 82 & 70 & 89 & 55 & 93 & 45 & 95 & 81 & 93 & 38 \\
2005 & 80 & 68 & 88 & 60 & 94 & 50 & 96 & 82 & 94 & 41 \\
2008 & & & 87 & 61 & 93 & 51 & & & & \\
\hline
\end{tabular}

Table 2: Wage Gap (Female-to-Male Wages; Percentage Points)

\begin{tabular}{cccccc}
\hline Year & USA & Brazil & Mexico & Thailand & India \\
1950 & 64 & & & & \\
& $\ldots$ & & & & \\
1990 & 69 & 67 & 84 & 72 & 36 \\
1995 & 73 & 71 & & 83 & 52 \\
2000 & 71 & 77 & 79 & 84 & 52 \\
2005 & 75 & 76 & 83 & 91 & 55 \\
2008 & & 78 & 85 & & \\
\hline
\end{tabular}

Table 3: Factor Composition

\begin{tabular}{cc}
\hline Brain & Brawn \\
Reasoning Development & Climbing/Balancing \\
Mathematical Development & Stooping/Kneeling/ \\
Language Development & Crouching/Crawling \\
Specific Vocational Preparation & Strength Requirement \\
General Intelligence & Indoor or Outdoor Work \\
Verbal Aptitude & Environmental Exposure \\
Numerical Aptitude & \\
Clerical Aptitude & \\
Talking and Hearing & \\
\hline
\end{tabular}


Table 4: Industry Ordinal Sorting and Cardinal Scales for Brain

\begin{tabular}{lcc}
\hline Industry & 1977 DOT & 1991 DOT \\
1. Agriculture, Hunting, etc. & 0.31 & 0.34 \\
2. Transport and telecommunications & 0.38 & 0.39 \\
3. Manufacturing & 0.39 & 0.39 \\
4. Mining & 0.39 & 0.39 \\
5. Retail, Hotels & 0.4 & 0.41 \\
6. Construction & 0.4 & 0.4 \\
7. Public services & 0.45 & 0.45 \\
8. Communal services & 0.5 & 0.51 \\
9. Finance and business serv. & 0.6 & 0.6
\end{tabular}

Table 5: Industry Ordinal Sorting and Cardinal Scales for Brawn

\begin{tabular}{lcc}
\hline Industry & $\mathbf{1 9 7 7}$ DOT & $\mathbf{1 9 9 1}$ DOT \\
1. Finance and business serv. & 0.6 & 0.6 \\
2. Retail, Hotels & 0.4 & 0.41 \\
3. Communal services & 0.5 & 0.51 \\
4. Manufacturing & 0.39 & 0.39 \\
5. Transport and telecommunications & 0.38 & 0.39 \\
6. Public services & 0.45 & 0.45 \\
7. Mining & 0.39 & 0.39 \\
8. Construction & 0.4 & 0.4 \\
9. Agriculture, Hunting, etc. & 0.31 & 0.34 \\
\hline
\end{tabular}

Table 6: Pooled Mincer Wage Regression (1977 DOT): $\hat{\beta}$

\begin{tabular}{lccc}
\hline Country & Year & Brain & Brawn \\
USA & 1990 & 0.617 & 0.151 \\
& 2005 & 0.633 & 0.074 \\
\cline { 2 - 4 } Brazil & 1990 & 0.644 & 0.072 \\
& 2005 & 0.504 & 0.031 \\
\cline { 2 - 4 } Mexico & 1990 & 0.312 & -0.111 \\
& 2005 & 0.616 & -0.110 \\
\cline { 2 - 4 } Thailand & 1990 & 0.798 & -0.848 \\
\multirow{3}{*}{ India } & 2005 & 0.185 & -0.546 \\
\cline { 2 - 4 } & 1990 & 0.345 & -0.379 \\
\hline
\end{tabular}

All coefficients are significant at $1 \%$ 
Table 7: Wage Gap Growth Decomposition (Percentage Points)

\begin{tabular}{|c|c|c|c|c|c|c|c|c|c|c|}
\hline Country & $\begin{array}{l}\text { Wage } \\
\text { Gap }\end{array}$ & $\Delta(Z)$ & $\Delta(\alpha)$ & $\begin{array}{c}\text { Brain } \\
\Delta(X)\end{array}$ & $\begin{array}{c}\text { Brawn } \\
\Delta(X)\end{array}$ & $\begin{array}{l}\text { Total } \\
\Delta(X)\end{array}$ & $\begin{array}{c}\text { Brain } \\
\Delta(\beta)\end{array}$ & $\begin{array}{c}\text { Brawn } \\
\Delta(\beta)\end{array}$ & $\begin{array}{l}\text { Total } \\
\Delta(\beta)\end{array}$ & $\begin{array}{l}\text { Total } \\
\text { Skills }\end{array}$ \\
\hline USA & 10.8 & 26.6 & 46 & 10.2 & 1.9 & 12.1 & 1 & 14.4 & 15.4 & 27.4 \\
\hline Brazil & 11.6 & 22.2 & 28 & 46 & -1.1 & 44.9 & -1.5 & 6.4 & 4.9 & 49.8 \\
\hline Mexico & -5.9 & -98.1 & 201.2 & 32.7 & 9.9 & 42.6 & -46.1 & 0.4 & -45.7 & -3.1 \\
\hline Thailand & 32.2 & 32.7 & 77.3 & -5.5 & -2.7 & -8.3 & 3.9 & -5.6 & -1.8 & -10 \\
\hline india & 51.1 & 57.3 & 29.4 & 5.6 & 13.5 & 19.1 & -1.4 & -4.5 & -5.8 & 13.3 \\
\hline
\end{tabular}

Table 8: Wage Gap Growth Decomposition with Varying Returns (Percentage Points)

\begin{tabular}{|c|c|c|c|c|c|c|c|c|c|c|}
\hline Country & $\begin{array}{l}\text { Wage } \\
\text { Gap }\end{array}$ & $\Delta(Z)$ & $\Delta(\alpha)$ & $\begin{array}{c}\text { Brain } \\
\Delta(X)\end{array}$ & $\begin{array}{c}\text { Brawn } \\
\Delta(X)\end{array}$ & $\begin{array}{l}\text { Total } \\
\Delta(X)\end{array}$ & $\begin{array}{c}\text { Brain } \\
\Delta(\beta)\end{array}$ & $\begin{array}{c}\text { Brawn } \\
\Delta(\beta)\end{array}$ & $\begin{array}{c}\text { Total } \\
\Delta(\beta)\end{array}$ & $\begin{array}{l}\text { Total } \\
\text { Skills }\end{array}$ \\
\hline Thailand & 32.2 & 46.8 & -0.2 & -5 & -1.1 & -6.1 & 22.1 & 37.4 & 59.5 & 53.5 \\
\hline india & 51.1 & -122.7 & 213.3 & 4.5 & 13.7 & 18.2 & -2.3 & -6.5 & -8.8 & 9.4 \\
\hline
\end{tabular}

Table 9: Mincer Wage Regression by Gender (1977 DOT): $\hat{\beta}$

\begin{tabular}{llccc}
\hline Country & Gender & Year & Brain & Brawn \\
& F & 1990 & 0.706 & -1.128 \\
Thailand & M & 1990 & 0.787 & -0.632 \\
& F & 2005 & 0.202 & -0.571 \\
& M & 2005 & 0.149 & -0.516 \\
\cline { 2 - 5 } India & F & 1990 & 0.137 & -0.103 \\
& M & 1990 & 0.296 & -0.458 \\
& F & 2005 & 0.285 & -0.320 \\
& M & 2005 & 0.447 & -0.644 \\
\hline
\end{tabular}

All coefficients are significant at $1 \%$

Table 10: Female Factor Contributions (Percentage Points)

\begin{tabular}{lccccc}
\hline & USA & Brazil & Mexico & Thailand & India \\
Rise in Female Ratio & 1.0 & 7.6 & 14.8 & 0.5 & 4.1 \\
\cline { 2 - 6 } Brain Rise & -0.7 & -1.8 & -0.3 & -0.9 & 0 \\
Brawn Rise & 1.1 & 2.8 & 3.8 & 4 & -0.6 \\
\cline { 2 - 6 } Total Predicted Rise & 0.4 & 1.1 & 3.5 & 3.1 & -0.5 \\
\hline
\end{tabular}


Table 11: Gender Regression (1977 DOT): $\hat{\gamma}$

\begin{tabular}{lcc}
\hline Country & Brain & Brawn \\
USA & -0.426 & -0.845 \\
Brazil & -0.595 & -0.706 \\
Mexico & -0.114 & -0.630 \\
Thailand & -0.416 & -0.225 \\
India & -0.177 & 0.186 \\
\hline All coefficients are significant at $1 \%$
\end{tabular}

Table 12: Education Factor Contributions (Percentage Points)

\begin{tabular}{lcccccccccc}
\hline & \multicolumn{2}{c}{ USA } & \multicolumn{2}{c}{ Brazil } & \multicolumn{3}{c}{ Mexico } & \multicolumn{2}{c}{ Thailand } & \multicolumn{2}{c}{ India } \\
& $\mathrm{M}$ & $\mathrm{F}$ & $\mathrm{M}$ & $\mathrm{F}$ & $\mathrm{M}$ & $\mathrm{F}$ & $\mathrm{M}$ & $\mathrm{F}$ & $\mathrm{M}$ & $\mathrm{F}$ \\
\cline { 2 - 11 } Rise in Education & 4.2 & 4.4 & 24.8 & 29.4 & 14 & 17.6 & 8.7 & 9.5 & 10.5 & 8.2 \\
\cline { 2 - 11 } Brain Rise & 0.4 & 1.2 & -0.7 & 4.8 & 1 & -0.1 & -0.3 & 2.5 & 0.1 & 0 \\
Brawn Rise & 0.1 & 0 & -0.2 & 1 & 0.8 & 0.4 & 9.1 & 5.8 & 1.4 & -0.4 \\
\cline { 2 - 11 } Total Predicted Rise & 0.6 & 1.3 & -0.9 & 5.7 & 1.8 & 0.3 & 8.9 & 8.3 & 1.5 & -0.4 \\
\hline
\end{tabular}

Table 13: Education Regression (1977 DOT): $\hat{\gamma}$

\begin{tabular}{lccc}
\hline Country & Gender & Brain & Brawn \\
USA & $\mathrm{M}$ & 0.395 & -0.076 \\
& $\mathrm{~F}$ & 0.402 & -0.076 \\
\cline { 2 - 4 } Brazil & $\mathrm{M}$ & 0.364 & -0.208 \\
& $\mathrm{~F}$ & 0.557 & -0.205 \\
\cline { 2 - 4 } Mexico & $\mathrm{M}$ & 0.466 & -0.177 \\
& $\mathrm{~F}$ & 0.538 & -0.236 \\
\cline { 2 - 4 } Thailand & $\mathrm{M}$ & 0.309 & -0.471 \\
& $\mathrm{~F}$ & 0.453 & -0.350 \\
\cline { 2 - 4 } India & $\mathrm{M}$ & 0.433 & -0.480 \\
& $\mathrm{~F}$ & 0.255 & -0.228 \\
\hline
\end{tabular}

All coefficients are significant at $1 \%$ 


\section{Figures}

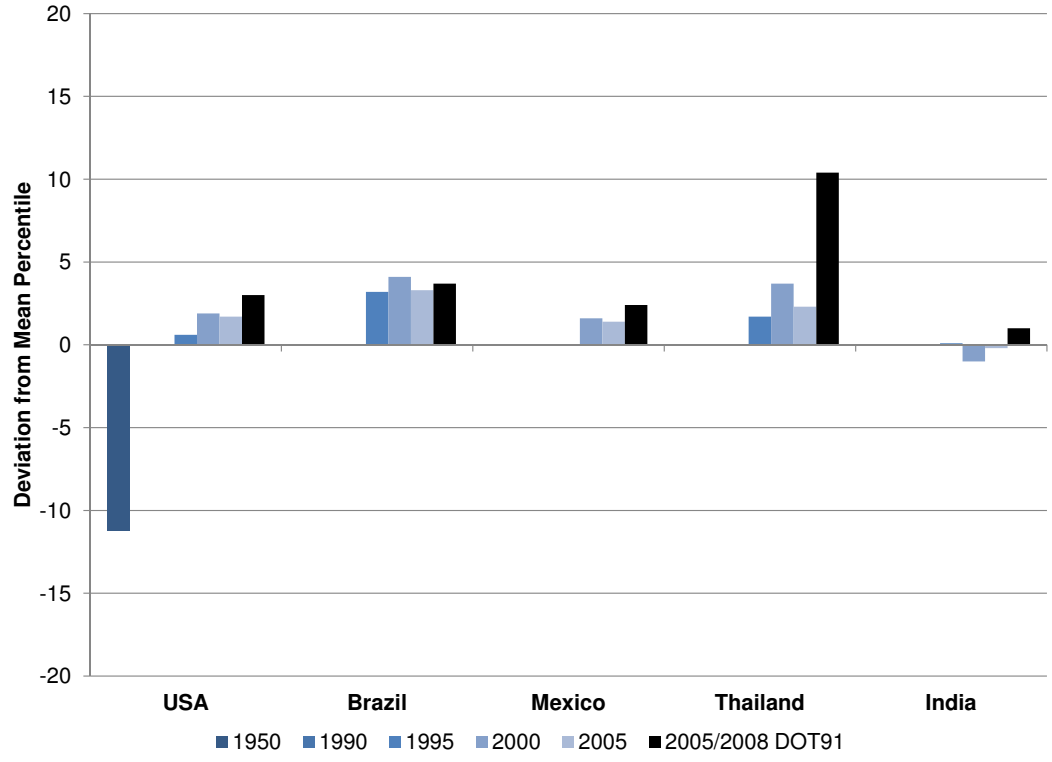

Figure 1: Brain Factor Changes (1990 to 2005)

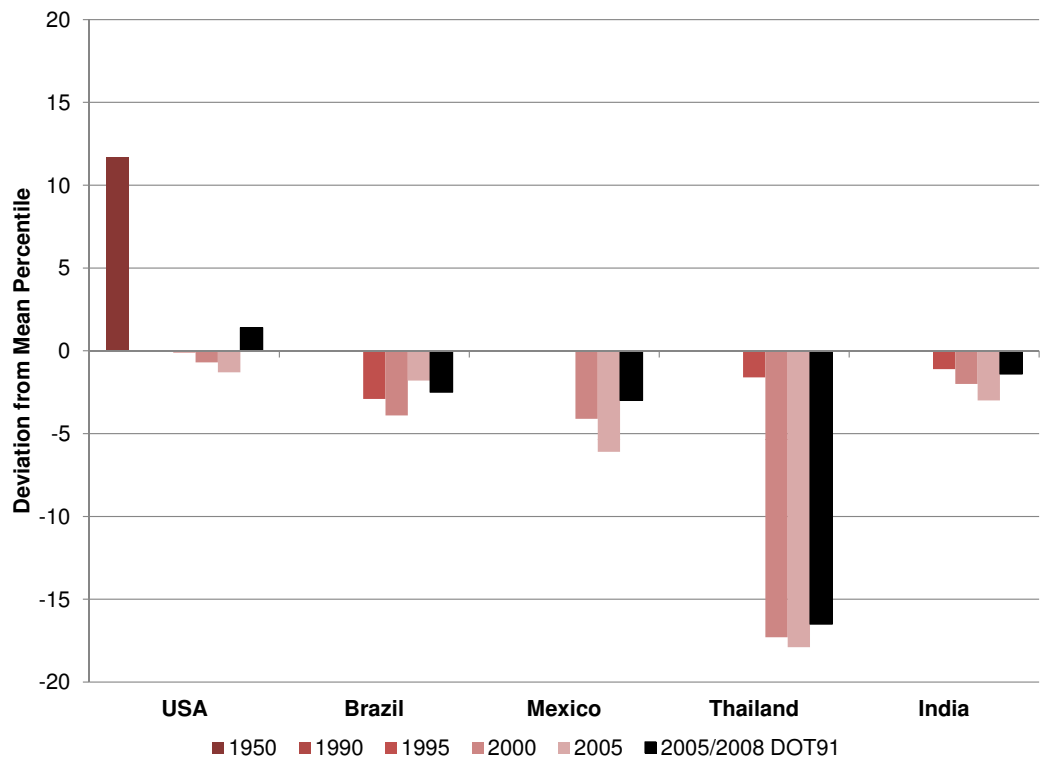

Figure 2: Brawn Factor Changes (1990 to 2005) 


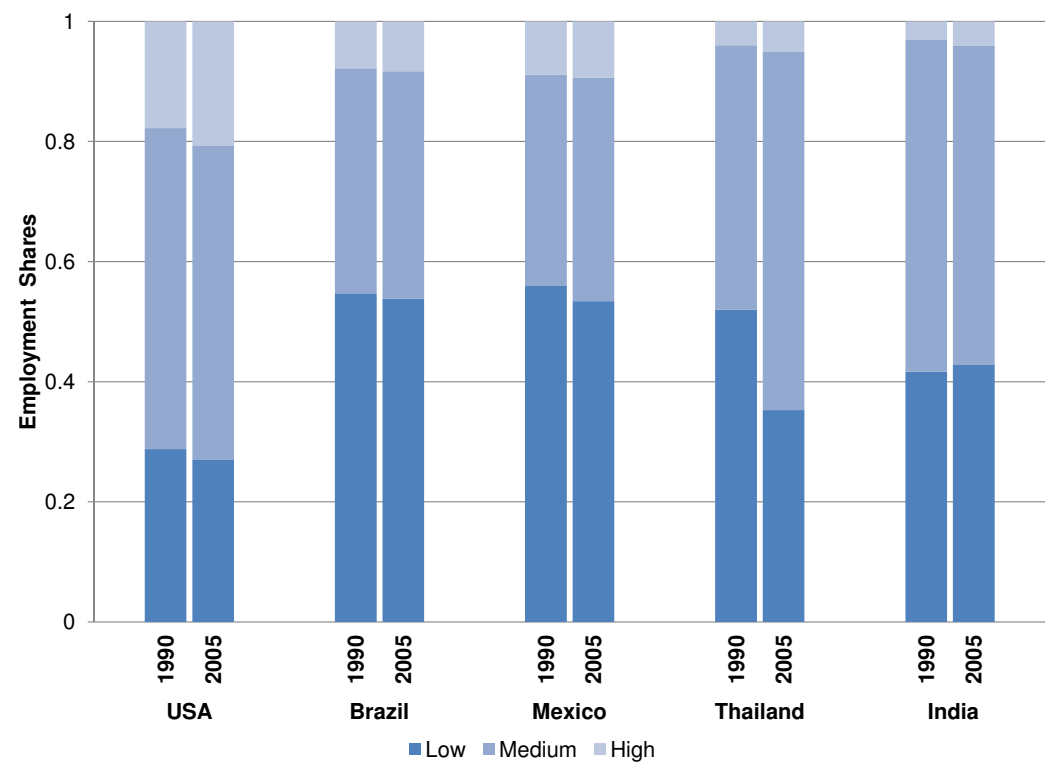

Figure 3: Employment Shares by Brain Factor Type (1990 to 2005)

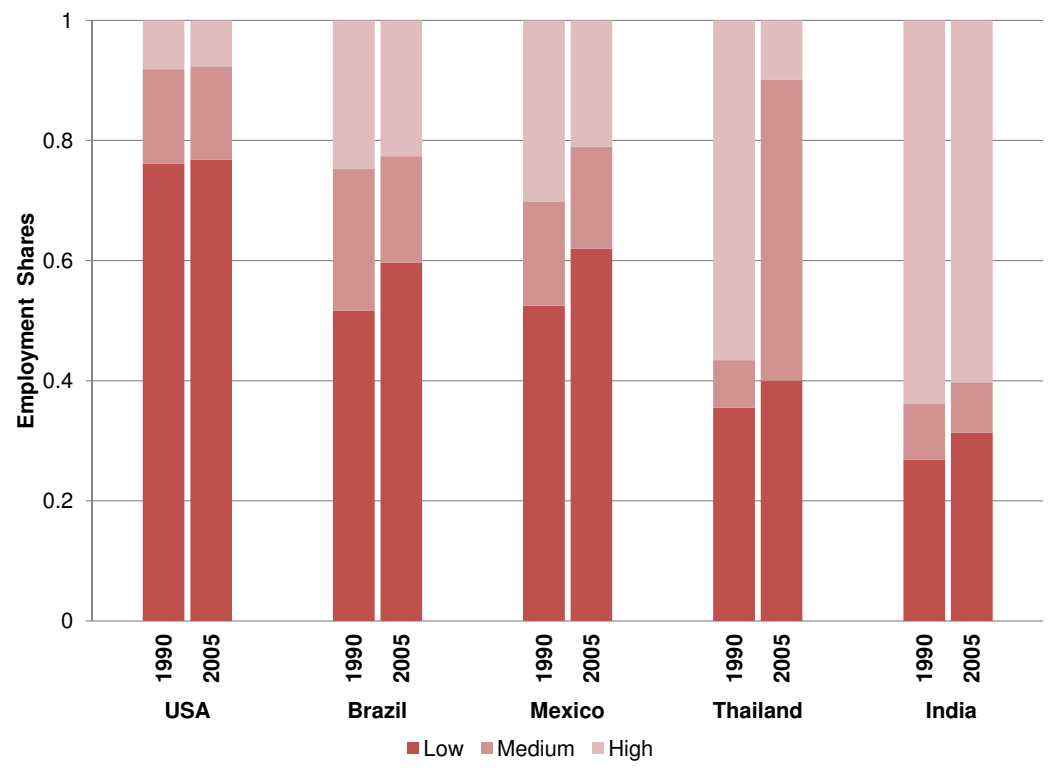

Figure 4: Employment Shares by Brawn Factor Type (1990 to 2005) 


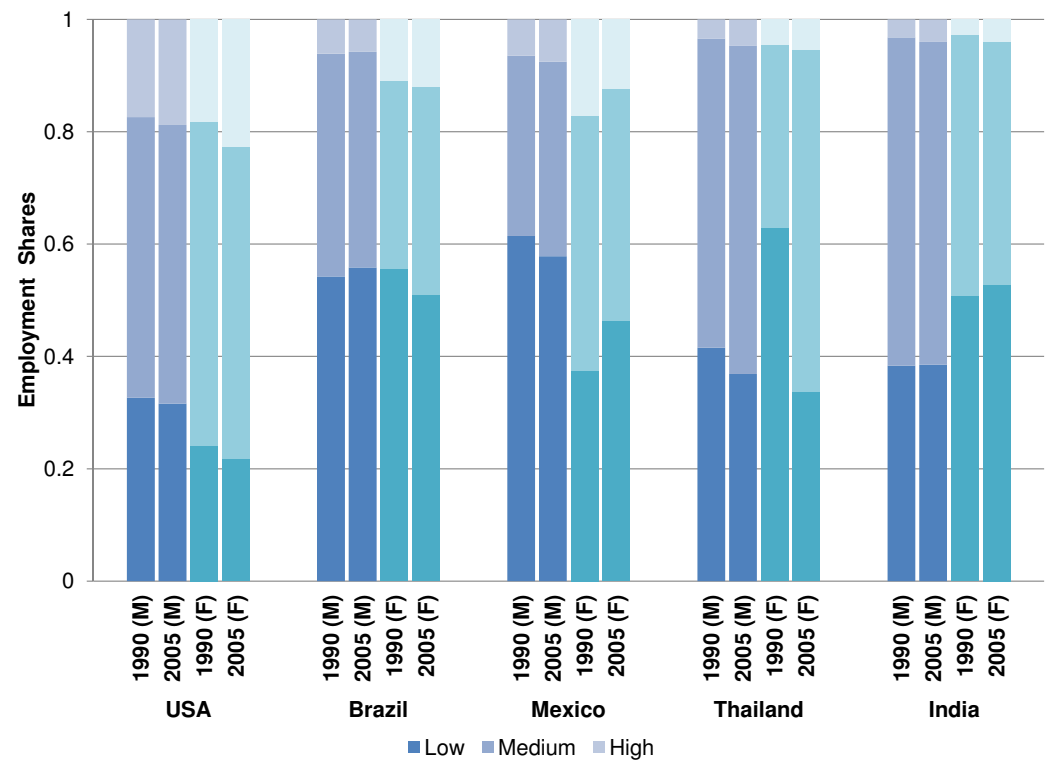

Figure 5: Employment Shares by Brain Factor Type and Gender (1990 to 2005)

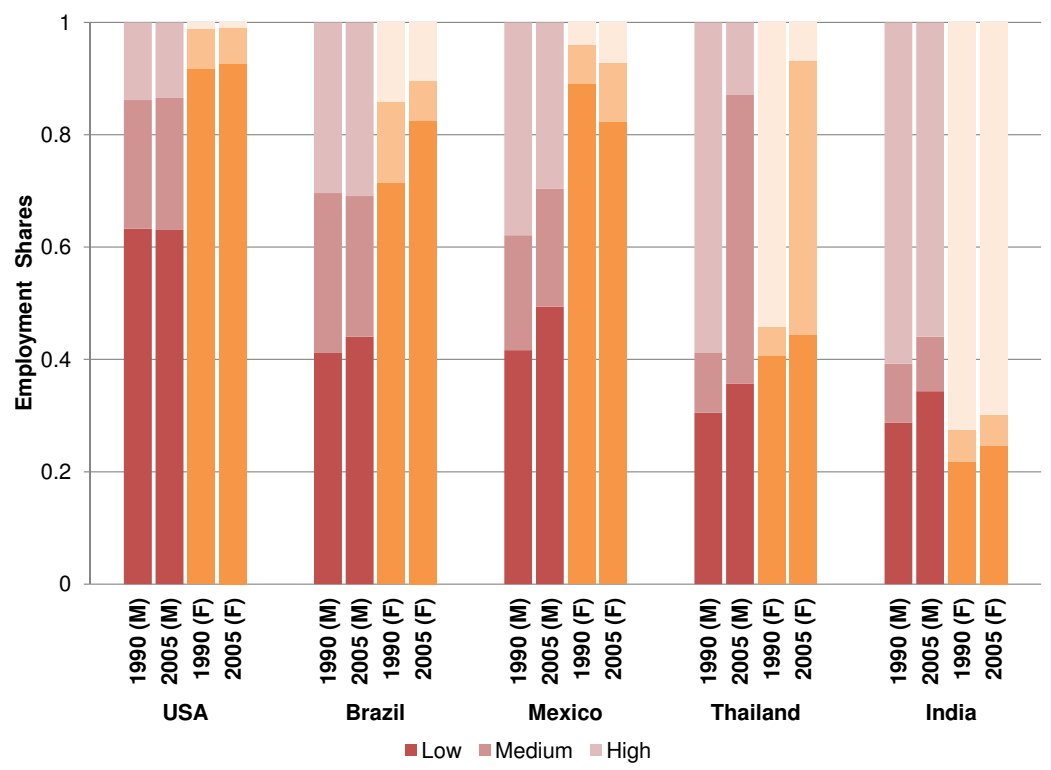

Figure 6: Employment Shares by Brawn Factor Type and Gender (1990 to 2005) 


\section{A Data Description}

The World Bank and the IMPUS International dataset provide individual-level data on demographic and economic variables such as gender, age, education, employment and wages for Brazil, Mexico and Thailand. Given data availability, the surveys used are from 1987, 1995, 1999, 2005 and 2008 for Brazil; 2000, 2005 and 2008 for Mexico; and 1990, 1994, 2002 and 2006 for Thailand. Details on these surveys can be found in Montenegro \& Hirn (2008). For all World Bank household surveys, wages are for paid employees, defined as cash wages for their primary job. In-kind wages or wages from secondary jobs are not included.

IPUMS International (Center, 2010) has data on the India employment survey for 1987, 1993, 1999 and 2004. This data has been previously used to study labor market outcomes in India in the formal sector and covers similar individual-level demographic and economic variables as the World Bank household survey. For more details on the specific survey set-up, see the IPUMS International webpage. IPUMS International also provides additional data for Mexico in 1990, allowing for a consistent comparison over the last 15 years.

A short discussion of each country-specific data sample is below, and Table A.1 provides an overview of all samples by year and country. The last column reports the percentage of employed workers with valid wage and salary information.

\section{A.1 Brazil}

For Brazil, in each survey year, 49 percent of all observations are male, weighted by population weights. The wage sample (including part-time workers) shrinks to about 45 percent of the observations for each year, but note that the employed in the employment sample make-up about 69 percent. Therefore, wage information exists for, on average, roughly 60 percent of the employed. Given women's lower labor market participation, the weighted sex ratios in the wage sample are more skewed, with 65 percent of the sample being men in 1987, and about 55 percent going forward. 
Table A.1: Sample Summary Statistics

\begin{tabular}{|c|c|c|c|c|c|c|}
\hline Country & Year & Emp Obs & M (\%) & Wage Obs & M (\%) & $\mathrm{W} / \mathrm{E}(\%)$ \\
\hline \multirow{5}{*}{ Brazil } & 1987 & 157,030 & 49 & 69,969 & 65 & 67 \\
\hline & 1995 & 179,247 & 49 & 68,460 & 56 & 57 \\
\hline & 1999 & 187,317 & 49 & 70,240 & 55 & 57 \\
\hline & 2005 & 224,281 & 49 & 91,597 & 54 & 61 \\
\hline & 2008 & 220,688 & 49 & 96,984 & 54 & 64 \\
\hline \multirow{4}{*}{ Mexico } & 1990 & $4,016,847$ & 48 & $1,417,291$ & 73 & 67 \\
\hline & 2000 & 22,664 & 47 & 9,714 & 68 & 66 \\
\hline & 2005 & 50,866 & 47 & 24,015 & 65 & 69 \\
\hline & 2008 & 65,555 & 47 & 32,907 & 64 & 74 \\
\hline \multirow{4}{*}{ Thailand } & 1990 & 32,637 & 47 & 10,730 & 57 & 38 \\
\hline & 1994 & 57,825 & 47 & 18,923 & 58 & 39 \\
\hline & 2002 & 72,776 & 47 & 27,571 & 54 & 45 \\
\hline & 2004 & 90,461 & 47 & 31,730 & 54 & 41 \\
\hline \multirow{4}{*}{ India } & 1987 & 365,508 & 49 & 48,939 & 62 & 23 \\
\hline & 1993 & 315,610 & 50 & 76,465 & 74 & 39 \\
\hline & 1999 & 333,853 & 50 & 84,348 & 73 & 41 \\
\hline & 2004 & 342,362 & 50 & 79,451 & 74 & 37 \\
\hline
\end{tabular}

\section{A.2 Mexico}

The World Bank survey provides data for Mexico starting in 2000. In each survey year, 47 percent of all observations are male, weighted by population weights. For 2000, the wage sample shrinks to roughly 40 percent or 9,000 observations. For the remaining observations, the wage sample retains roughly 50 percent of the observations (including part-time workers). The employed in the employment sample make-up about 65 to 69 percent. Therefore, wage information exists for roughly 70 percent of the employed. Given women's lower labor market participation, the weighted sex ratios fall from 68 percent in 2000 to 64 percent in 2008 .

IPUMS International has Census data for Mexico in 1990, and this sample is substantially larger then the World Bank Household survey, but similar in composition. The employment sample has roughly four million observations, and the wage sample has 1.4 million observations. Men make up 48 percent of the employment sample, but 73 percent of the wage sample. Roughly 2.1 million individuals of the employment sample are employed. Therefore, roughly 67 percent of employed individuals have wage information. Wages here refer to an individual's total income in the previous month or year, reported in monthly numbers including wages and income from a business or farm. 


\section{A.3 Thailand}

In each survey year, 47 percent of all observations are male, weighted by population weights. The wage sample for Thailand is substantially smaller than in Brazil and Mexico, with only a third of the observations in the employment sample having wage and salary information. Moreover, roughly 80 percent of the employment survey are employed, suggesting only about 40 percent of the employed have wage and salary information. Given women's lower labor market participation, the weighted sex ratios fall from 57 percent in the surveys in the 1990 s to 54 percent in the surveys from the 2000s. Also note, Thailand only provides one-digit industry classifications, but threedigit occupation classifications. Since the DOT refers to occupations, there will be some loss of information when superimposing the factor requirements, but the loss should be small given the three-digit occupation information.

\section{A.4 India}

The data comes from the Socio-Economic Survey, Household Schedule 10, and it captures roughly 0.06 to 0.09 percent of the population. It samples all the civilian non-institutionalized population in India, except foreigners. To form a representative sample, sample weights are provided by the National Sample Survey Organization. In each survey year, 50 percent of all observations, weighted by population weights, are male. The wage sample for India is also substantially smaller than for Brazil and Mexico, with only one quarter of the observations in the employment sample having wage and salary information. However, only 60 percent of the employment survey were employed in 1983 rising to 63 percent in 2004. This suggests a similar fraction of wage information as in Thailand, i.e., slightly below 40 percent of the employed have wage and salary information. Given women's substantially lower labor market participation, the weighted male sex ratio is roughly 75

percent. The statistics used refer to wage and salary income (not total earnings) received during the reference week. This includes both cash and in-kind payments. 


\section{B Additional Descriptive Statistics}

This appendix provides additional labor market statistics. Tables $B .1$ and B.2 provide the ordinal ranking and cardinal scales for aggregate occupations in the United States. Tables B.3-B.6 provide aggregate sector and occupation specific employment shares by gender.

Table B.1: Occupation Ordinal Sorting and Cardinal Scales for Brain

\section{Occupation}

1. Elementary occupations

2. Plant and machine operators and assemblers

3. Service workers and shop and market sales

4. Crafts and related trades workers

5. Skilled agricultural and fishery workers

6. Clerks

7. Technicians and associate professionals

8. Legislators, senior officials and managers

9. Professionals
1977 DOT 1991 DOT

0.17

0.19

0.33

0.41

0.41

0.44

0.61

0.62

0.72
0.17

0.2

0.34

0.41

0.51

0.44

0.61

0.63

0.74

Table B.2: Occupation Ordinal Sorting and Cardinal Scales for Brawn

\begin{tabular}{lcc}
\hline Occupation & 1977 DOT & 1991 DOT \\
1. Clerks & 0.44 & 0.44 \\
2. Legislators, senior officials and managers & 0.62 & 0.63 \\
3. Professionals & 0.72 & 0.74 \\
4. Technicians and associate professionals & 0.61 & 0.61 \\
5. Service workers and shop and market sales & 0.33 & 0.34 \\
6. Plant and machine operators and assemblers & 0.19 & 0.2 \\
7. Crafts and related trades workers & 0.41 & 0.41 \\
8. Elementary occupations & 0.17 & 0.17 \\
9. Skilled agricultural and fishery workers & 0.41 & 0.51 \\
\hline
\end{tabular}


Table B.3: Occupational Employment Shares (Percentage Points)

\begin{tabular}{lcccccccccc}
\hline \multirow{2}{*}{ Occupation } & \multicolumn{2}{c}{ USA } & \multicolumn{2}{c}{ Brazil } & \multicolumn{2}{c}{ Mexico } & \multicolumn{2}{c}{ Thailand } & \multicolumn{2}{c}{ India } \\
& 1990 & 2005 & 1990 & 2005 & 1990 & 2005 & 1990 & 2005 & 1990 & 2005 \\
\cline { 2 - 11 } Senior officials & 13 & 13 & 5 & 6 & 3 & 7 & 1 & 9 & 6 & 8 \\
Professionals & 14 & 14 & 4 & 6 & 7 & 7 & 4 & 4 & 3 & 3 \\
Technicians & 7 & 11 & 3 & 7 & 3 & 4 & 6 & 3 & 1 & 1 \\
Clerks & 19 & 18 & 8 & 8 & 10 & 7 & 3 & 4 & 2 & 2 \\
Service and market sales workers & 16 & 17 & 10 & 31 & 12 & 20 & 7 & 13 & 3 & 4 \\
Skilled agricultural & 2 & 1 & 23 & 16 & 22 & 13 & 18 & 37 & 37 & 35 \\
Craft workers & 11 & 11 & 21 & 21 & 19 & 14 & 12 & 10 & 11 & 13 \\
Machine operators & 11 & 10 & 5 & 5 & 11 & 9 & 6 & 8 & 3 & 4 \\
Elementary occupations & 8 & 5 & 20 & 0 & 12 & 20 & 43 & 12 & 28 & 24 \\
\hline
\end{tabular}

Table B.4: Sectoral Employment Shares (Percentage Points)

\begin{tabular}{|c|c|c|c|c|c|c|c|c|c|c|}
\hline \multirow[t]{2}{*}{ Industry } & \multicolumn{2}{|c|}{ USA } & \multicolumn{2}{|c|}{ Brazil } & \multicolumn{2}{|c|}{ Mexico } & \multicolumn{2}{|c|}{ Thailand } & \multicolumn{2}{|c|}{ India } \\
\hline & 1990 & 2005 & 1990 & 2005 & 1990 & 2005 & 1990 & 2005 & 1990 & 2005 \\
\hline Agriculture & 3 & 2 & 24 & 16 & 23 & 13 & 48 & 44 & 61 & 56 \\
\hline Mining & 1 & 0 & 1 & 0 & 1 & 0 & 0 & 0 & 1 & 1 \\
\hline Manufacturing & 18 & 12 & 17 & 15 & 21 & 18 & 11 & 14 & 12 & 12 \\
\hline Public utilities & 1 & 1 & 1 & 0 & 1 & 0 & 1 & 0 & 0 & 0 \\
\hline Construction & 7 & 8 & 7 & 7 & 8 & 8 & 4 & 6 & 5 & 6 \\
\hline Commerce & 22 & 22 & 17 & 23 & 16 & 19 & 16 & 20 & 8 & 11 \\
\hline Transports and communications & 5 & 5 & 5 & 5 & 5 & 6 & 3 & 3 & 3 & 4 \\
\hline Financial/business services & 10 & 11 & 6 & 7 & 2 & 6 & 0 & 2 & 1 & 2 \\
\hline Community services & 33 & 38 & 23 & 26 & 24 & 29 & 17 & 11 & 9 & 8 \\
\hline
\end{tabular}

Table B.5: Male Sectoral Employment Shares (Percentage Points)

\begin{tabular}{|c|c|c|c|c|c|c|c|c|c|c|}
\hline \multirow[t]{2}{*}{ Industry } & \multicolumn{2}{|c|}{ USA } & \multicolumn{2}{|c|}{ Brazil } & \multicolumn{2}{|c|}{ Mexico } & \multicolumn{2}{|c|}{ Thailand } & \multicolumn{2}{|c|}{ India } \\
\hline & 1990 & 2005 & 1990 & 2005 & 1990 & 2005 & 1990 & 2005 & 1990 & 2005 \\
\hline Agriculture & 2 & 2 & 19 & 12 & 22 & 11 & 24 & 22 & 41 & 34 \\
\hline Mining & 1 & 0 & 1 & 0 & 1 & 0 & 0 & 0 & 1 & 1 \\
\hline Manufacturing & 12 & 9 & 12 & 10 & 16 & 11 & 5 & 7 & 9 & 9 \\
\hline Public utilities & 1 & 1 & 1 & 0 & 1 & 0 & 0 & 0 & 0 & 0 \\
\hline Construction & 6 & 7 & 7 & 7 & 7 & 8 & 3 & 4 & 4 & 5 \\
\hline Commerce & 12 & 12 & 11 & 14 & 11 & 10 & 6 & 9 & 7 & 10 \\
\hline Transports and communications & 4 & 3 & 4 & 5 & 5 & 5 & 3 & 3 & 3 & 4 \\
\hline Financial/business services & 4 & 5 & 4 & 5 & 1 & 4 & 0 & 1 & 1 & 1 \\
\hline Community services & 13 & 15 & 6 & 7 & 14 & 13 & 9 & 5 & 7 & 6 \\
\hline
\end{tabular}


Table B.6: Female Sectoral Employment Shares (Percentage Points)

\begin{tabular}{lcccccccccc}
\hline Industry & \multicolumn{2}{c}{ USA } & \multicolumn{2}{c}{ Brazil } & \multicolumn{2}{c}{ Mexico } & \multicolumn{2}{c}{ Thailand } & \multicolumn{2}{c}{ India } \\
& 1990 & 2005 & 1990 & 2005 & 1990 & 2005 & 1990 & 2005 & 1990 & 2005 \\
\cline { 2 - 11 } Agriculture & 1 & 1 & 5 & 4 & 1 & 3 & 24 & 22 & 19 & 22 \\
Mining & 0 & 0 & 0 & 0 & 0 & 0 & 0 & 0 & 0 & 0 \\
Manufacturing & 6 & 4 & 4 & 6 & 5 & 7 & 6 & 8 & 3 & 4 \\
Public utilities & 0 & 0 & 0 & 0 & 0 & 0 & 0 & 0 & 0 & 0 \\
Construction & 1 & 1 & 0 & 0 & 0 & 0 & 1 & 1 & 1 & 1 \\
Commerce & 11 & 10 & 5 & 9 & 5 & 9 & 10 & 11 & 1 & 1 \\
Transports and communications & 2 & 1 & 0 & 1 & 0 & 1 & 0 & 0 & 0 & 0 \\
Financial/business services & 5 & 6 & 2 & 2 & 1 & 2 & 0 & 1 & 0 & 0 \\
Community services & 20 & 24 & 17 & 19 & 10 & 16 & 8 & 6 & 2 & 3 \\
\hline
\end{tabular}

\section{Mincer Wage Regression Results}

The following tables provide factor coefficient estimates (prices) of the Mincer wage regressions used in the wage gap decomposition of Table 7.

Table C.1: Pooled Wage Regression USA (1977 DOT)

\begin{tabular}{|c|c|c|c|c|}
\hline Variable & $\begin{array}{c}\text { Coefficient } \\
1990\end{array}$ & $\begin{array}{c}\text { (Std. Err.) } \\
(1990)\end{array}$ & $\begin{array}{c}\text { Coefficient } \\
2005\end{array}$ & $\begin{array}{c}\text { (Std. Err.) } \\
(2005)\end{array}$ \\
\hline Age & 0.061 & $(0.001)$ & 0.059 & $(0.001)$ \\
\hline Age Sq. & -0.001 & $(0.000)$ & -0.001 & $(0.000)$ \\
\hline Black & -0.085 & $(0.007)$ & -0.090 & $(0.006)$ \\
\hline Race Other & -0.048 & $(0.012)$ & -0.043 & $(0.008)$ \\
\hline Years of Education & 0.054 & $(0.001)$ & 0.070 & $(0.001)$ \\
\hline Married & -0.074 & $(0.005)$ & -0.105 & $(0.004)$ \\
\hline Male & 0.346 & $(0.005)$ & 0.297 & $(0.004)$ \\
\hline Brain & 0.617 & $(0.011)$ & 0.633 & $(0.010)$ \\
\hline Brawn & 0.151 & $(0.010)$ & 0.074 & $(0.009)$ \\
\hline Intercept & 3.541 & $(0.027)$ & 3.438 & $(0.027)$ \\
\hline $\mathrm{N}$ & \multicolumn{2}{|c|}{46601} & \multicolumn{2}{|c|}{63871} \\
\hline $\mathrm{R}^{2}$ & \multicolumn{2}{|c|}{0.404} & \multicolumn{2}{|c|}{0.396} \\
\hline $\mathrm{F}_{(9, .)}$ & \multicolumn{2}{|c|}{3506.651} & \multicolumn{2}{|c|}{4645.901} \\
\hline
\end{tabular}


Table C.2: Pooled Wage Regression Brazil (1977 DOT)

\begin{tabular}{lcccc}
\hline Variable & $\begin{array}{c}\text { Coefficient } \\
\mathbf{1 9 9 0}\end{array}$ & $\begin{array}{c}\text { (Std. Err.) } \\
\mathbf{( 1 9 9 0 )}\end{array}$ & $\begin{array}{c}\text { Coefficient } \\
\mathbf{2 0 0 5}\end{array}$ & $\begin{array}{c}\text { (Std. Err.) } \\
(\mathbf{2 0 0 5})\end{array}$ \\
\hline Age & 0.091 & $(0.002)$ & 0.058 & $(0.001)$ \\
Age Sq. & -0.001 & $(0.000)$ & 0.000 & $(0.000)$ \\
Urban & 0.175 & $(0.011)$ & 0.095 & $(0.008)$ \\
Years of Education & 0.090 & $(0.001)$ & 0.085 & $(0.001)$ \\
Male & 0.413 & $(0.008)$ & 0.372 & $(0.041)$ \\
Brain & 0.644 & $(0.017)$ & 0.504 & $(0.004)$ \\
Brawn & 0.072 & $(0.018)$ & 0.031 & $(0.010)$ \\
Intercept & 1.370 & $(0.038)$ & 1.940 & $(0.022)$ \\
\hline N & \multicolumn{2}{c}{29380} & \multicolumn{2}{c}{0.48171} \\
R ${ }^{2}(7,)$. & \multicolumn{2}{c}{0.603} & \multicolumn{2}{c}{8568.514} \\
\hline
\end{tabular}

Table C.3: Pooled Wage Regression Mexico (1977 DOT)

\begin{tabular}{lcccc}
\hline Variable & $\begin{array}{c}\text { Coefficient } \\
\mathbf{1 9 9 0}\end{array}$ & $\begin{array}{c}\text { (Std. Err.) } \\
\mathbf{( 1 9 9 0 )}\end{array}$ & $\begin{array}{c}\text { Coefficient } \\
\mathbf{2 0 0 5}\end{array}$ & $\begin{array}{c}\text { (Std. Err.) } \\
(\mathbf{2 0 0 5})\end{array}$ \\
\hline Age & 0.040 & $(0.000)$ & 0.073 & $(0.002)$ \\
Age Sq. & 0.000 & $(0.000)$ & -0.001 & $(0.000)$ \\
Urban & -0.172 & $(0.002)$ & 0.296 & $(0.013)$ \\
Years of Education & 0.053 & $(0.000)$ & 0.068 & $(0.001)$ \\
Married & -0.097 & $(0.002)$ & -0.094 & $(0.010)$ \\
Male & 0.193 & $(0.002)$ & 0.299 & $(0.010)$ \\
Brain & 0.312 & $(0.003)$ & 0.616 & $(0.023)$ \\
Brawn & -0.111 & $(0.003)$ & -0.110 & $(0.021)$ \\
Intercept & 3.419 & $(0.007)$ & 3.639 & $(0.049)$ \\
\hline N & \multicolumn{2}{c}{1166991} & \multicolumn{2}{c}{27756} \\
$\mathrm{R}^{2}$ & \multicolumn{2}{c}{0.219} & \multicolumn{2}{c}{1898.323} \\
F ${ }_{(8, .)}^{41006.015}$ &
\end{tabular}

Table C.4: Pooled Wage Regression Thailand (1977 DOT)

\begin{tabular}{|c|c|c|c|c|}
\hline Variable & $\begin{array}{c}\text { Coefficient } \\
1990\end{array}$ & $\begin{array}{c}\text { (Std. Err.) } \\
(1990)\end{array}$ & $\begin{array}{c}\text { Coefficient } \\
2005\end{array}$ & $\begin{array}{c}\text { (Std. Err.) } \\
(2005)\end{array}$ \\
\hline Age & 0.092 & $(0.005)$ & 0.052 & $(0.002)$ \\
\hline Age Sq. & -0.001 & $(0.000)$ & 0.000 & $(0.000)$ \\
\hline Urban & 0.494 & $(0.017)$ & 0.240 & $(0.006)$ \\
\hline Years of Education & 0.064 & $(0.002)$ & 0.078 & $(0.001)$ \\
\hline Married & -0.103 & $(0.020)$ & -0.057 & $(0.007)$ \\
\hline Male & 0.440 & $(0.017)$ & 0.190 & $(0.006)$ \\
\hline Brain & 0.798 & $(0.042)$ & 0.185 & $(0.014)$ \\
\hline Brawn & -0.848 & $(0.048)$ & -0.546 & $(0.018)$ \\
\hline Intercept & 3.822 & $(0.087)$ & 5.127 & $(0.035)$ \\
\hline $\mathrm{N}$ & \multicolumn{2}{|c|}{10439} & \multicolumn{2}{|c|}{31653} \\
\hline $\mathrm{R}^{2}$ & \multicolumn{2}{|c|}{0.494} & \multicolumn{2}{|c|}{0.535} \\
\hline $\mathrm{F}_{(8, .)}$ & \multicolumn{2}{|c|}{1274.108} & \multicolumn{2}{|c|}{4553.8} \\
\hline
\end{tabular}


Table C.5: Pooled Wage Regression India (1977 DOT)

\begin{tabular}{|c|c|c|c|c|}
\hline Variable & $\begin{array}{c}\text { Coefficient } \\
1990\end{array}$ & $\begin{array}{c}\text { (Std. Err.) } \\
(1990)\end{array}$ & $\begin{array}{c}\text { Coefficient } \\
2005\end{array}$ & $\begin{array}{c}\text { (Std. Err.) } \\
(2005)\end{array}$ \\
\hline Age & 0.056 & $(0.002)$ & 0.036 & $(0.001)$ \\
\hline Age Sq. & -0.001 & $(0.000)$ & 0.000 & $(0.000)$ \\
\hline Urban & -0.350 & $(0.008)$ & -0.362 & $(0.005)$ \\
\hline No Education & -1.017 & $(0.014)$ & -1.123 & $(0.010)$ \\
\hline Primary Education & -0.724 & $(0.014)$ & -0.911 & $(0.010)$ \\
\hline Secondary Education & -0.274 & $(0.013)$ & -0.517 & $(0.010)$ \\
\hline Married & -0.171 & $(0.008)$ & -0.089 & $(0.010)$ \\
\hline Male & 0.599 & $(0.008)$ & 0.477 & $(0.005)$ \\
\hline Brain & 0.345 & $(0.016)$ & 0.443 & $(0.012)$ \\
\hline Brawn & -0.379 & $(0.017)$ & -0.595 & $(0.012)$ \\
\hline Intercept & 9.690 & $(0.037)$ & 5.874 & $(0.028)$ \\
\hline $\mathrm{N}$ & \multicolumn{2}{|c|}{47517} & \multicolumn{2}{|c|}{78007} \\
\hline $\mathrm{R}^{2}$ & \multicolumn{2}{|c|}{0.583} & \multicolumn{2}{|c|}{0.557} \\
\hline $\mathrm{F}_{(10, .)}$ & \multicolumn{2}{|c|}{6640.234} & \multicolumn{2}{|c|}{9789.103} \\
\hline
\end{tabular}

